\title{
Isolated Caecal Necrosis Mimicking Acute Appendicitis in a Patient with Chronic Renal Failure
}

\author{
Kronik Renal Yetmezlikli Hastada Akut Apandisiti Taklit Eden İzole Çekum \\ Nekrozu
}

Mefaret Şahin', Ceren Şen Tanrıkulu², YusufTanrıkulu'1, Serap Erel'

'Ankara Eğitim ve Araştırma Hastanesi, 4. Genel Cerrahi Kliniği, Ankara, Türkiye ${ }^{2}$ Ankara Eğitim ve Araştırma Hastanesi, Acil Tıp Kliniği, Ankara, Türkiye

\section{ABSTRACT}

Acute colonic ischaemia is a common cause of colitis in the elderly, in whom colonic ischaemia is a cause of morbidity. Necrosis of the caecum is a rare variant of ischaemic colitis causing right lower quadrant pain. Acute appendicitis, diverticulitis, stercoral perforation and colon carsinomas should therefore be taken into consideration in the differential diagnosis, especially in elderly patients. However, ischaemic colitis involving the caecum alone is quite rare, as is caecal ischaemia after hypotension caused by dialysis or trauma. We present in this article a 71-year-old woman who had acute abdominal symptoms following an episode of severe hypotension during haemodialysis and developed caecum necrosis spontaneously.

Keywords: Apendicitis, chronic kidney failure, ischaemic colitis Received: 29.07.2011 Accepted: 02.11.2011

\section{ÖZET}

Akut kolon iskemisi yaşlılardaki kolitin yaygın bir nedeni olup, bu yaş grubunda morbiditenin önemli bir kısmını oluşturmaktadır. İskemik kolitin çok az görülen bir tipi olan çekum nekrozu sağ alt kadranda ağrıya neden olmaktadır. Bu nedenle özellikle yaşı ıastalarda sağ alt kadran ağrısı yapan akut apandisit, çekum divertiküliti, sterkoral perforasyon ve kolon karsinomları ayırıcı tanıda göz önünde bulundurulmalıdır. Yalnızca çekumu tutan iskemik kolit oldukça nadir olup çekal iskemi travma yada diyaliz sonrası hipotansiyona bağıı oluşabilmektedir. Bu yazıda hemodiyaliz sırasında şiddetli bir hipotansif atak sonrasında akut batın bulguları ortaya çıkan, spontan çekum nekrozu gelişmiş kronik böbrek yetmezliği olan 71 yaşındaki bir erkek hasta sunulmaktadır.

Anahtar Kelimeler: Apandisit, kronik böbrek yetmezliği, iskemik kolit

Geliş Tarihi: 29.07.2011 Kabul Tarihi: 02.11.2011

\section{Giriş}

İskemik kolit genellikle aterosklerozis ve düşük kan akımı sonucu oluşmaktadır. Akut kolon iskemisi yaşlılardaki kolitin yaygın bir nedeni olup bu kişilerdeki kolon iskemisi morbiditenin önemli bir kısmını oluşturmaktadır. Bununla birlikte yalnızca çekumu tutan iskemik kolit oldukça nadirdir. Sağ kolonun izole iskemik tutulumunun sıklığı özellikle şok gibi durumlarda düşük kan akımılla ilişkili olarak giderek artmaktadır (1).

İskemik kolitin çok az görülen bir varyantı olan çekum nekrozu sağ alt kadranda ağrıya neden olmaktadır. Bu nedenle özellikle yaşıı hastalarda akut apandisit, çekum divertiküliti ve sterkoral perforasyon ayırıcı tanıda göz önünde bulundurulmalıdır (2).

\section{Olgu Sunumu}

Altı yıldır kronik böbrek yetmezliği nedeniyle hemodiyaliz tedavisi alan 71 yaşında erkek hasta, ani başlayan ve 24 saattir devam eden, şiddetinde giderek artma olan sağ alt kadran ağrısı şikayetiyle kliniğimize başvurdu. Hastada bulantı, kusma ve diyare 


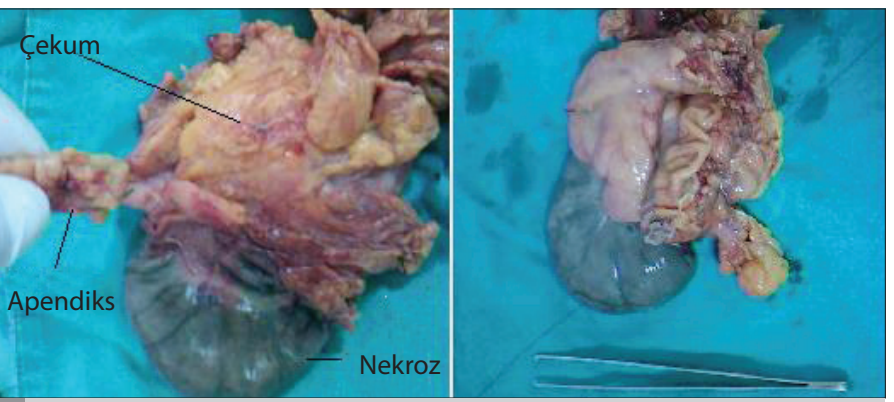

Resim 1. İzole çekum nekrozunun intraoperatif görünümü

mevcut değildi. Hastaya bir gün önce hemodiyaliz uygulandığı ve hemodiyaliz sırasında hipotansif bir atak geçirdiği belirlendi. Hasta son defekasyonunu bir gün önce yaptığını ve defekasyonda ve gaitada farklılık olmadığını belirtti. Ateşi $38^{\circ} \mathrm{C}$, kan basıncı 90/60 mmHg ve nabız 98 atım/dk. idi. Hastanın yapılan fizik muayenesinde sağ alt kadranda hassasiyet, defans ve rebound mevcuttu. Rektal tuşesi normaldi. Laboratuar bulgularında beyaz küre sayısı

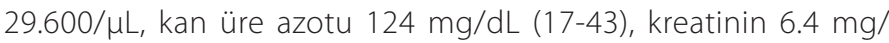
$\mathrm{dL}$ (0.81-1.44) ve sedimentasyonu $77 \mathrm{~mm} / \mathrm{saat}$ (0-15) idi. Ayakta direkt karın grafisi normaldi ve akciğer grafisinde diyafram altında serbest hava görülmedi. Yapılan abdominal ultrasonografide herhangi bir patolojik bulgu mevcut değildi. Hasta akut apandisit ön tanısıyla preoperatif hazırlık ve hidrasyonu takiben ameliyata alındı. Orta hat insizyonla yapılan gözlemde apendiks normal olup çekumda yaklaşık 10 cm'lik segmenti içeren parsiyel nekroz alanı mevcuttu (Resim 1). Bunun üzerine hastaya sağ hemikolektomi yapıldı ve hasta postoperatif 7. günde taburcu edildi. Kolona ait patoloji spesmeninde mukozal ülserasyon, transmural inflamasyon ve koagülasyon nekrozu izlendi.

\section{Tartışma}

Kolonik iskemi yaşlılarda önemli bir morbidite nedenidir. Kolonik iskeminin nedenleri oklüziv ve non-oklüziv olarak sınıflandırılabilir. Oklüziv iskemi, ateroskleroz, tromboembolizm, venöz oklüzyon ve mekanik barsak tıkanması gibi faktörlere bağlı olarak oluşur. Nonoklüziv kolonik iskemi ise şok gibi mezenterik vazokonstruksiyonun olduğu durumlarda düşük kan akımına bağlı meydana gelir (1, 2).

İskemik kolit, kolon kan akımında azalmaya bağlı görülen nonokluziv mezenterik iskeminin iyi bilinen bir tipidir. Bu durumdaki hastalar geniş iki gruba ayrılmaktadır. Tip I iskemik kolitli hastalarda kolit kendiliğinden oluşmakta olup mezenterik kan akımında azalmaya neden olan presipitan faktör bulunamamıştır. Tip II iskemik kolitli hastalarda ise kolite neden olan sistemik hipotansiyon ve azalmış kardiak output gibi sekonder bir etken mevcuttur $(2,3)$.

Tip I iskemik kolit özelikle sol kolon olmak üzere kolonun herhangi bir kısmını etkilemektedir. Splenik fleksuranın, inferior ve superior mezenterik sistem arasındaki kollaterallerden beslendiğine inanılır ve bu kısım en yaygın tutulan alandır (2-4). Sağ kolonun non-okluziv iskemik nekrozu hem Tip I ve hem de Tip II iskemik kolitli hastalarda görülebilir. Tip I iskemik kolitli hastalarda genellikle karın ağrısı, rektal kanama, diyare, distansiyon ve lökositoz mevcuttur. Bu hastalık ge- nellikle kendi kendini sınılar. Parenteral antibiyotik kullanılması ve barsakların istirahati semptomlar geçene kadar tavsiye edilir $(2,3)$.

Çekal iskemi travma ya da diyaliz sonrası hipotansiyona bağlı oluşabilmektedir (1, 3, 5). Bu hastalardaki çekal nekrozun mekanizması primer olarak düşük kan akımıyla ilişkilidir. Semptomlar diyaliz ya da travmadan kısa bir süre sonra görülür (5). Hipotansiyonla ilişkisiz çekumun izole iskemik nekrozu, çekal distansiyon ya da arteriyel oklüzyon genelde olağan değildir.

İzole çekal nekroz çekal arterlerin tromboembolik oklüzyonunu ya da aterosklerozunu takip eder. Non-oklüziv çekal nekrozun açık kalp cerrahisi, kronik kalp hastalığı, bazı ilaçlar (digoxin gibi) ve hemodiyaliz ile ilişkili olabileceği çeşitli çalışmalarda rapor edilmiştir (6). Hemodiyaliz hastalarında, arteriyel vasküler hastalık oranı artığından iskemik kolit riski yüksektir (5). Ek olarak diyaliz esnasında çok büyük miktarda sıvı çekildiğinden hipotansiyon gelişmekte bu da iskemiye katkıda bulunmaktadır. Dirican ve ark'ları (7) sunmuş oldukları vaka serisinde dört hastanın üçünde kronik böbrek yetmezliği olduğunu rapor etmişlerdir. Bizim olgumuzda ise hasta kronik böbrek yetmezliği olan hastaydı ve hemodiyalize girmekteydi.

İskemik kolit genellikle ileri yaşlarda görülmektedir. Abel ve ark.'nın (8) sunduğu 18 hastadan sadece bir tanesi 50 yaşın altındaydı. Olguda sunduğumuz hasta ise 71 yaşındaydı.

Çekal nekrozun yanında yaşlı hastalarda sağ alt kadranın ayırıcı tanısında apandisit, çekal divertikülit, sterkoral perforasyon ve çekal karsinom göz önünde bulundurulmalıdır. Apandisitin kliniği çekal gangrene benzer özellikte olup ayırımı zordur. Akut apandisit kliniğinde gözlenen iştahsızlık, ağı bulantı üçlüsü iskemik kolitte her zaman bulunmayabilir. Ayrıca ağrının başlayışı iskemik kolitte daha anidir ve şiddeti hızla artar. Inflamasyona ait bulgular ise her ikisinde de hemen hemen benzerdir (2).

Mezenter ekosunda kalınlaşma, barsak duvar boyutunda incelme ve nekrozun olduğu barsak kısmında kan akımında azalma gibi bulguların görülmesiyle ultrason tanıda yardımcı olabilir (9). Tomografi bulguları non-spesifik olmasına rağmen çekum duvar kalınlığının incelmesi ve izole pnömotozis koli tanıyı destekler. Abdominal tomografi bu tür hastalarda apandisiti gösterebilir (10). Çekal divertikülitler genellikle kırklı yaşlarda olma eğilimindedir fakat kliniği çekal nekrozdan ayırt edilemeyebilir.

İskemik koliten şüphelenilen hastalarda kolonoskopinin kullanımı tartışmalıdır. Bir grup yazar bu hastalarda kolonoskopiyi tavsiye ederken, diğer bir yazarda kolonoskopinin transmural basıncı artırarak kolonik perfüzyonu azalttığı ve perforasyon riskini arttırdığından dikkatli olunması gerektiği bildirmişlerdir. Ayrıca tanısal laparoskopi tanı ve tedavi için kullanılabilmektedir $(2,8)$.

İzole çekal nekrozun tedavisinde çekal rezeksiyon ya da sağ hemikolektomi yapılmaktadır. Eğer peritonit mevcutsa sağ hemikolektomi tatmin edici olabilir (8). Bizde olgumuzun cerrahi tedavisinde sağ hemikolektomiyi tercih ettik. İzole çekal nekrozun cerrahi tedavisinden sonra geride kalan kolonun postoperatif iskemik nekrozu hakkında 
yeterli bilgi mevcut değildir. İskemik kolitli altı çalışmada gangrenöz kolitin mortalitesi ise \%37 olarak bulunmuştur $(2,3)$.

\section{Sonuç}

İskemik kolitin nadir bir varyasyonu olan izole çekum nekrozunun yaşlı, kronik renal yetmezlikli diyaliz hastalarında gelişen akut batın tablosunda barsak iskemisi veya nekrozu ile karşılaşılabileceği göz önünde bulundurulmalıdır. Genellikle genel durumu bozuk bu hastalarda kolon rezeksiyonu gibi morbidite ve mortalitesi yüksek major bir cerrahi girişime hazırlıklı olunmalıdır.

\section{Çıkar Çatışması}

Yazarlar herhangi bir çıkar çatışması bildirmemişlerdir.

\section{Kaynaklar}

1. Flynn TC, Rowlands BJ, Gilliland M, Ward RE, Fischer RP. Hypotensioninduced post-traumatic necrosis of the right colon. Am J Surg 1983; 146: 715-8. [Crossref]
2. Bower TC. Ischemic colitis. Surg Clin North Am 1993; 73: 1037-53.

3. Sakai L, Keltner R, Kaminski D. Spontaneous and shock-associated ischemic colitis. Am J Surg 1980; 140: 755-60. [Crossref]

4. Marcuson RW, Farman JA. Ischaemic disease of the colon. Proc R Soc Med 1971; 64: 1080-3.

5. Friedell ML. Cecal necrosis in the dialysis-dependent patient. Am Surg 1985; 51: 621-2

6. Rist CB, Watts JC, Lucas RJ. Isolated ischemic necrosis of the cecum in patients with chronic heart disease. Dis Colon Rectum 1984; 27: 548-51. [Crossref]

7. Dirican A, Unal B, Bassulu N, Tatlı F, Aydin C, Kayaalp C. Isolated cecal necrosis mimicking acute appendicitis: a case series. J Med Case Reports 2009; 19: 7443. [Crossref]

8. Abel ME, Russell TR. Ischemic colitis. Comparison of surgical and nonoperative management. Dis Colon Rectum 1983; 26: 113-5. [Crossref]

9. Ranschaert E, Verhille R, Marchal G, Rigauts H, Ponette E. Sonographic diagnosis of ischemic colitis. J Belge Radiol 1994; 77: 166-8.

10. Simon AM, Birnbaum BA, Jacobs JE. Isolated infarction of the cecum: CT findings in two patients. Radiology 2000; 214: 513-6. 